\title{
The Language Errors of a Swiss German Speaker of Greek as an L2: A Case Study
}

\author{
By Georgios Georgiou*
}

\begin{abstract}
The present study aims to identify the most important language errors in the speech of a second language (L2) Greek speaker, and explain these errors on the basis of the speaker's first language (L1) interference, the speakers' sociolinguistic background, and the effect of language mechanisms. The study employs the data of a semi-structured interview from a Swiss German speaker who permanently lives in Cyprus for 13 years and speaks Greek as an L2. The recordings of the interview were transcripted to identify possible errors in the phonetic/phonological, morphological, syntactical, and semantic level. The results showed errors in every language level indicating a clear interference of the speaker's L1 in the L2, an overgeneralization of grammatical rules, and an interference of the local dialect in the $\mathrm{L} 2$ productions.
\end{abstract}

Keywords: Greek, language acquisition; language errors; second language.

\section{Introduction}

The acquisition of first language (L1) begins from infancy and does not require any effort to be achieved (O'Grady and Cho 2011). It provides the opportunity to the infant to become a native speaker of a language at a later developmental stage. Children are able to form grammatically correct sentences from the age of 3-4 having received only few speech stimuli in their native language. In that way, they construct their own rules, which as they grow up will be refuting before reaching an adequate level of L1 knowledge (Fromkin et al. 2008). On the other hand, the knowledge of a second (L2)/foreign language does not take place naturally, but it requires readiness, effort, significant study and memorization of rules and vocabulary (Fromkin et al. 2008, Lightbown and Spada 2006). It is argued that L1 acquisition might be similar to some extent with L2 acquisition since in both modes there are stages of language development as well as development of grammars by the speakers (Fromkin et al. 2008). Nevertheless, this assumption is not widely supported. Some researchers argue that the acquisition of the L1 requires the use of different skills in comparison to the acquisition of the L2. Also, the transfer of structures from one language to another is feasible only from the L1 to the L2 and not vice versa, while there is a stagnation during the learning of the L1, which is not the case for the L2 (Mohamad-Nor and Rashid 2018). All L1 speakers reach the same level of acquisition, while proficiency level in the L2 differs from learner to learner.

The purpose of the present study is the identification, presentation, and interpretation of the language errors of an L2 Greek speaker as emerge from a

"Postdoctoral Researcher, People’s Friendship University of Russia (RUDN University), Russia.

https://doi.org/10.30958/ajp.7-2-3

doi=10.30958/ajp.7-2-3 
qualitative analysis of his productions. This investigation will take into consideration four levels of linguistic analysis. The study will provide evidence for the existence of specific errors, which are indicated by the literature and relate to the learning of Greek as an L2, showing as well the manner in which the speaker's $\mathrm{L} 1$ interferes in the $\mathrm{L} 2$ productions.

The study aims to answer the following research questions:

1. Which are the errors of the L2 Greek speaker with respect to the levels of phonetics/phonology, morphology, syntax, and semantics?

2. To the basis of which theories can these errors be explained?

3. How the L2 speaker's sociolinguistic characteristics affect his L2 production patterns?

\section{Literature Review}

With respect to the level of phonetics/phonology, it is predicted a difficulty of L2 speakers, and especially those who do not have much experience in the L2, with the production of some L2 sounds. According to Best and Tyler (2007) and Flege (2005), there is a common phonological system for both the L1 and the L2 phones, and thus, linguistic experience in the native language might shape the acquisition of the L2 sounds. If an L2 sound or a pair of L2 sounds is similar to an L1 sound, then learners might face difficulties in both perceiving and producing correctly the L2 sounds. There are few studies in regard to the phonological patterns of Greek speakers who learn a nonnative language (e.g., Georgiou 2019a, $2019 \mathrm{~b}$ ), and similarly few studies related with L2 errors of foreign learners of Greek. For example, Anastiasiadi-Simeonidi et al. (2010) recorded the phonetic/ phonological errors of Russian speakers who learn Greek as an L2, identifying problems with the production of sounds that are not present in their L1. Nicolaides et al. (2011) after comparing the Greek phonological system with the systems of another 11 languages, created a table with possible difficulties in the production of the Greek sounds by foreign learners of these languages. Finally, Georgiou (2018) found that Egyptian Arabic learners of Greek as an L2 were merging the Greek vowels $/ \mathrm{i} /-/ \mathrm{e} /$ and $/ \mathrm{o} /-/ \mathrm{u} /$ due to the effect of their $\mathrm{L} 1$.

In regard to the level of morphology, Babiniotis (1996) pointed out that Greek consists of a wide morphological system of which the learning is relatively difficult for foreign speakers. According to Theodoropoulou and Papanastasiou (2001), most of the errors that have to do with morphology are affected by the mechanism of analogy. Speakers tend to replace, for example, the inflectional ending of a word with another as a consequence of the effect of analogy, e.g., $t u$

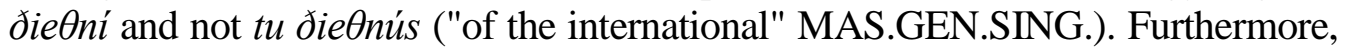
errors are found as well in the use of verbal aspect. Verbal aspect in Greek determines if the action of the verb was or will be continuous or non-continuous. The majority of foreign learners uses incorrectly the continuous and noncontinuous aspect that refer to the past and the future, and sentences with $n a+$ supplement, e.g, $\theta$ a klápsi* poli sixná 's/he will cry very often' (use of the noncontinuous verbal aspect instead of the continuous) (Mattheoudaki et al. 2011). 
With respect to the syntactic level, Tantos (2011) studied the use of clitic doubling by German learners of Greek to observe the existence of difficulties in the use of this structure since it is not found in the learners' L1. The author concluded that learners try to 'filter' the L2 structures through their L1 system. Therefore, if the same structure is found in both the L1 and the L2, then a positive transfer to the L2 might take place without any difficulty for the learners. But, if an L1 structure is different from an L2 structure, then a negative transfer might take place, which will probably create problems for the learners.

Finally, at the semantic level, there are many cases in which foreign speakers use words that do not exist or words that do not fit to the semantic context of the sentence (Anastasiadi-Simeonidi et al. 2008). Bakakou-Orfanou (1996) pointed out the need of instruction of the Greek synonyms to foreign learners in order for the words to be understandable in linguistic and extra-linguistic context, and not to be confused with other words. The same should be done, according to Pita (1998), with children who learn their L1 and who should understand the words corellationally by recognizing synonymies and contradictions. Other strategies suggested for vocabulary learning is the linking of a word with an image, the use of dictionaries, the use of crosswords, the mimics, and others (Zerdeli and Sarafidou 2011).

The learning of an L2 is affected by a variety of biological factors. For example, many researchers support the existence of a "critical period". When learners pass this period, they lose the ability to acquire holistically an L2 (Scovel 2000, Birdsong 2004). However, in the last few years, such a hypothesis could be explained in a different way since there are examples in which older learners acquired fully the L2 accent (Flege et al. 1995). The L2 learning is affected by several sociolinguistic factors such as age of living in an L2-speaking country, the L1-L2 use, the quality and quantity of L2 input, etc. (Piske et al. 2002). For instance, if a foreigner lives for many years in an L2 country, uses the L2 very often, and receives qualitative and quantitative L2 input, they will be able to learn more easily the L2. However, L2 learning is different in adults vs. children since the latter population can learn the L2 more easily, more rapidly, and with less effort than adults (Snow 1987, Tsukada et al. 2005).

Finally, it has to be noted that in Cyprus there is a special linguistic context with the coexistence of two linguistic varieties; a situation of diglossia. Specifically, Standard Modern Greek is the "official" variety and Cypriot Greek the "unofficial" variety (Pavlou and Christodoulou 1996). Standard Greek is used in the Medias and in the educational context, while Cypriot Greek is used mainly through the speakers' oral discussions. Yiakoumetti (2003) studied the oral and written productions of Cypriot Greek students, concluding that they were transferring structures from Cypriot Greek to Standard Modern Greek. It is expected that diglossia will affect as well foreign learners of Greek who learn Greek in controlled environments in Cyprus since there is a remarkable difference between what they hear into the classroom and what they hear outside the classroom. 


\section{Methodology}

The sample of the study consisted of a foreign male speaker with Swiss German L1 background who speaks Greek as an L2. The speaker lives permanently for 13 years in Cyprus, he is 49 years old, and he is married with a Cypriot Greek speaker. He speaks Greek many hours per day, and has a lot of friends who are Cypriot Greek speakers. He started learning Greek when he arrived in Cyprus; at the beginning through oral conversations with friends and relatives.

A semi-structured interview was used for the analysis of the productions of the speaker. The interview included questions of general interest (e.g., why he came to Cyprus, what are his favorite hobbies, etc.). The interview took place in a quiet room at the University of Cyprus and lasted approximately 40 minutes. The interview was recorded and then transcripted to facilitate the analysis of the speaker's L2 productions. The analysis focused on four linguistic levels: phonetics/ phonology, morphology, syntax, and semantics.

\section{Results}

\section{Phonetics/Phonology}

The production of some sounds differed compared to the corresponding productions of native speakers. The main problem was found in the production of velar and dental consonants. For example, the velar stop phoneme $/ \gamma /$ was substituted in many cases with the velar fricative /g/, while the alveolar stop /d/ was used instead of the dental fricative /ð/. Furthermore, the velar fricative /x/ was substituted with the uvular fricative $/ \chi /$. However, in many cases, these sounds could be produced correctly:

(1) pu vriskómaste to lab pu éxume 20 ipolo/g/*istés (132) "we are at the lab where we have 20 computers"

(2) íne káti pu/d/*en (125-126) "it is something that is not"

(3) íne ótan pas sti $/ \chi^{* * o r a ~ k e ~(148) ~ " i t ~ i s ~ l i k e ~ g o i n g ~ t o ~ t h e ~ c o u n t r y ~ a n d " ~}$

\section{Morphology}

At least in two cases, the interviewee used incorrectly the past-tense stem instead of the present-tense stem for the formation of subjunctive $(n a+v e r b)$, declaring in that way non-continuous instead of continuous aspect:

(1) ðen émaӨe akóma na yrápsi* (317) "she did not learn to write yet"

(2) ksekínise na milísi* poli norís yia éna moró (386) "she started speaking very early for a child"

One other error was the use of the inflectional ending -(i)és (FEM. PRU.) (-

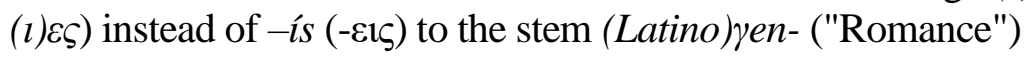


(1) Latinoyen-iés* (374) ("Romance (languages)")

Apart from the aforementioned errors, in general, the interviewee was using correctly the morphemes; including inflectional endings.

Syntax

Only few errors were observed at the level of syntax. It was observed the continuous use of the personal pronoun eyó ("I") in contexts where it is often avoided by native speakers:

(1) ke eyó stin arxí iða óti to próvlima (75-76) "and at the beginning I saw that the problem"

(2) exó Júlepsa mia forá se éna sxolio ekí (179) "I worked once in a school there"

(3) aspúme eyó ðiðaska yalliká ekí (180) "for example I was teaching French there"

In addition, it was observed the use of (itan) na (would) + verb in the position of $\theta \alpha$ (would) + past continuous; the latter is a common structure in Standard Modern Greek, while the former is mostly used in Cypriot Greek:

(1) ke metá itan na páme na fáme (81-82), "and then we would go to eat"

(2) éxume éna spíti pu den kséro ti ítan na to kánume (250) "we have a house that I don't know what we would do with it"

In very few cases he was using the $\theta \alpha+$ past continuous:

(1) a a borúsame na púme óti ta Katalánika (411) "we could say that Catalan"

In general the syntax of the interviewee was correct and followed the rules of Greek language.

\section{Semantics}

Regarding the semantic level, the interviewee in some cases used words that did not have the appropriate semantic meaning in order for the sentence to make sense.

(1) to leksikó* itane poli mikró (388-389) "the dictionary (instead of the 'vocabulary') was very small"

(2) epikinonúse xorís kanéna próvlima me morá áynosta* ke ynostá* stin Ispanikí (390) "she was communicating without any problem with known (instead of 'children who know') and unknown (instead of 'children who do not know') children in Spanish"

In addition, while he was using Standard Modern Greek during the interview, in a few cases he was using words or phrases of Cypriot Greek:

(1) edáksi, ektós pu spíti (56) "ok, except from home" 
(2) kápu allú prépi na piásis éna aeropláno «(214) "somewhere else you have to take an airplane"

\section{Discussion}

The aim of the study was to identify, present, and interpret the most important language errors of an L2 Greek speaker with Swiss German L1 background. It focused on four linguistic levels, that is, phonetics/phonology, morphology, syntax, and semantics. The results revealed errors in all four levels under investigation.

The production of some sounds with a nonnative manner took place due to the differences between the phonological system of the speaker's L1, that is Swiss German, and the phonological system of the speaker's L2, that is Greek. The fact that the consonants $/ \delta / \kappa \alpha \mathrm{l} / \gamma /$ do not exist in the speakers' L1 forces him to use the most acoustically similar sounds that are found in his L1, that is $/ \mathrm{d} /$ and $/ \mathrm{g} /$ respectively. So, the speaker did not perceive much acoustic dissimilarity between these L2 sounds and the aforementioned similar L1 sounds, and therefore, his productions were not native-like. However, in many cases, the speaker produced correctly these sounds due to his experience in the L2.

The errors in verbal aspects (non-continuous instead of continuous) during the formation of the subjunctive mood can be interpreted as a confusion by the foreign speaker due to the complexity of this phenomenon in Greek. Similarly, in the study of Mattheoudaki et al. (2011) it is shown a difficulty in the discrimination of the non-continuous and continuous aspect in Greek $n a+$ supplement structure even by high proficient learners of Greek as an L2. Most of the errors were observed in the use of non-continuous verbal aspect instead of the continuous one. In a similar way, this structure seems to be difficult for the interviewee of this study who tends to overgeneralize the rule for the use of the non-continuous aspect, and therefore, use it in continuous contexts. In contrast, he did not use the continuous aspect in the position of the non-continuous aspect.

The incorrect use of the ending -iés (-(1)źs) instead of -is (-Eís) to the stem (Latino)yen-, can be explained as an overgeneralization of the rule, which posits that most of the feminine adjectives in plural are formed with the addition of the ending -(i)es. This is also evident in children who learn their L1, and who tend to regularize the irregular nouns or verbs (Fromkin et al. 2008). In our case, the interviewee considered as correct the use of the ending-(i)és, because it constitutes a usual addition in Modern Greek. The ending -is is an addition that comes from Ancient Greek, and therefore is more difficult for a foreigner to learn.

With respect to the syntactic level, the interviewee used the pronoun eyó ("I") even in linguistic contexts where it is not required. Greek usually omits personal pronouns in the position of subject, while Greek speakers usually use them when they want to emphasize on the subject. This pattern can be explained as an L1 transfer since the use of personal pronouns in German is compulsory, and therefore, this structure was transferred to the L2. Furthermore, the use of $n a+$ $v e r b$ in the position of $\theta \alpha+$ past continuous can be interpreted as an interference 
from the Cypriot Greek variety since the na (or enná) + verb structure usually substitutes the $\theta \alpha+$ past continuous structure in Cypriot Greek. This interference took place since the interviewee lives for many years in Cyprus where Cypriot Greek is the dominant variety in the oral speech, and furthermore, his wife and friends are all native speakers of Cypriot Greek.

The use of words that did not have the appropriate semantic meaning did not cause any surprise since it can take place even for native speakers of a language due to the lack of vocabulary or misconceptions. In any case, the vocabulary continues to enrich to a great extent during the lifespan of speakers. Furthermore, the extended use of the Cypriot Greek variety in Cyprus, "impels" the foreign speaker to use words or phrases of that variety when speaking Greek. However, during the interview, the speaker had only very few syntactic and morphological errors. This can be explained on the basis of similarities between Greek and German in the structural level. In both languages, there are three grammatical articles (one for each gender: masculine, feminine and neutral), and four grammatical cases for nouns (nominative, accusative, genitive, dative) (Manika 2006); the dative case was abolished from Modern Greek, however, it can be expressed through prepositions. In addition, just like Greek verbs, the verbs of German are composed with objects in the accusative case (and more rarely with the dative case).

Several sociolinguistic factors affect the learning of an L2. The speaker of this study has been living in Cyprus for 13 years, and since then, he has been receiving Greek input mainly through conversations with relatives and friends who are Cypriot Greek native speakers. The speaker pointed out that he speaks Greek very often; this would justify his enhanced proficiency in the target-language. Furthermore, we have to consider that he has been living for a long time in the L2speaking country receiving much speech input in the L2. Furthermore, the speaker's age was not restrictive for the acquisition of the L2. Despite the fact that he began learning Greek from the age of 36, his errors in the four linguistic levels under investigation were minimal and were not preventing the communication with native speakers. The most significant errors were found in the phonetic/ phonological level since the speaker could not pronounce correctly several Greek consonants. In general, this level is difficult for foreign learners to acquire if they do not receive phonetic training or if they do not come in contact with the L2 before puberty. Finally, the speaker's L1 played a significant role because the study showed that it interfered in the L2 productions.

\section{Conclusions}

In sum, the errors emerged from the productions of the L2 Greek speaker are challenging for many L2 Greek speakers as reported by several studies in the literature, and they are driven by language mechanisms such as overgenelization. Also, it was evident that there was an interference of the speaker's L1 in the L2 since structures from his native language were transferred to the L2. Furthermore, there was an interference of the Cypriot Greek variety in his productions since 
Cypriot Greek constitutes the dominant spoken variety in the country where the foreign speaker lives. In general, his experience in the L2 helped him conduct only few mistakes at all linguistic levels and produce correct L2 forms; helping him communicate adequately with native speakers.

The study focused on a case study; however, to generalize the results, a future study should involve many participants, and a qualitative and quantitative analysis of the speakers' errors should be employed.

\section{References}

Anastasiadi-Simeonidi A, Vletsi E, Mitsiaki M, Bozonelos V, Chouma V (2008) Ta

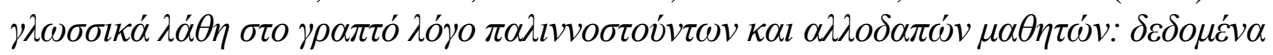

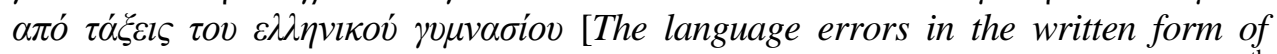
returning and foreign students: data from classes of the Greek Gymnasium]. $7^{\text {th }}$ international conference for the Greek language: The instruction of Modern Greek in the world 'Schools, methods, examinations', Mesologgi, 18-20 September 2008.

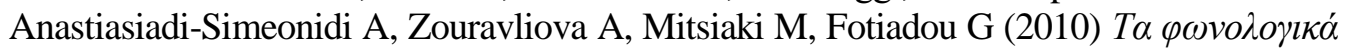

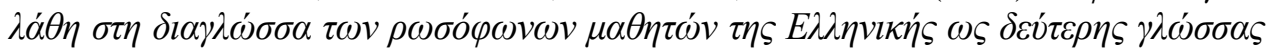
[The phonological errors in the interlanguage of Russian-speaking students of Greek as a second language]. In Advances in research on language acquisition and teaching: Selected papers, A Psaltou, M Mattheoudakis (eds), 53-64. Thessaloniki, Greece.

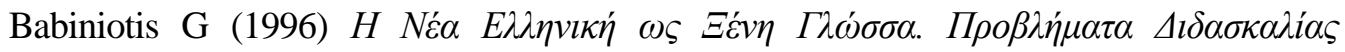
[Modern Greek as a Foreign Language. Instruction problems]. Goulandri-Horn Foundation.

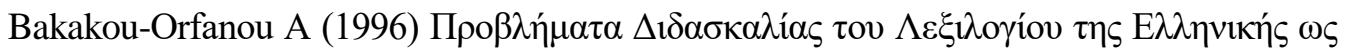
$\Xi \varepsilon \dot{v} \eta \varsigma$ Г $\lambda \omega ́ \sigma \sigma \alpha \varsigma$ [Instruction problems of the vocabulary of Greek as Foreign

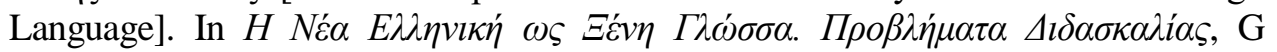
Babiniotis (ed). Goulandri-Horn Foundation

Best C, Tyler M (2007) Non-native and second-language speech perception: Commonalities and complementarities. In Second language speech learning: In honor of James Emil Flege, O-S Bohn, MJ Munro (eds), 13-34. Amsterdam: John Benjamins.

Birdsong D (2004) Second language acquisition and ultimate attainment. In The handbook of applied linguistics, A Davies, C Elder (eds), 82-105. Malden, MA: Blackwell.

Flege JE, Munro MJ, MacKay IRA (1995) The effect of age of second language learning on the production of English consonants. Speech Communication 16(1): 1-26.

Flege JE (2005) Origins and development of the Speech Learning Model. $1^{\text {st }}$ ASA Workshop on L2 Speech Learning (April 14-15, 2005). Vancouver, BC.: Simon Fraser University.

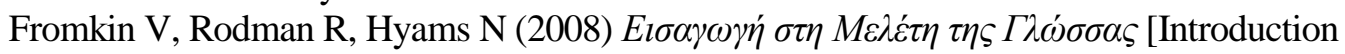
to the Study of Language). Athens: Patakis.

Georgiou GP (2018) Discrimination of L2 Greek vowel contrasts: Evidence from learners with Arabic L1 background. Speech Communication 102: 68-77.

Georgiou GP (2019a) 'Bit' and 'beat' are heard as the same: Mapping the vowel perceptual patterns of Greek-English bilingual children. Language Sciences 72: 1-12.

Georgiou GP (2019b) Cue-reliance and vowel perceptual patterns of Cypriot Greek children who learn English. Journal of Experimental Phonetics 28: 229-253. 
Lightbown PM, Spada N (2006) How languages are learned. Oxford, UK: Oxford University Press.

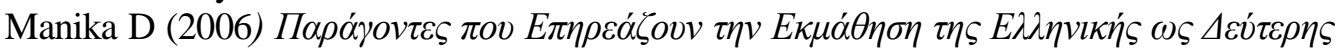

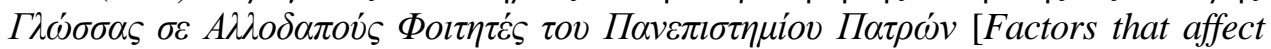
the learning of Greek as a Second Language in Foreign Students of the University of Patras]. Master's thesis, University of Patras.

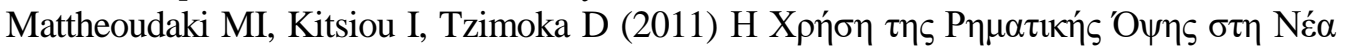

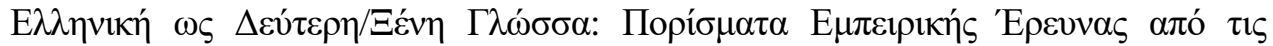

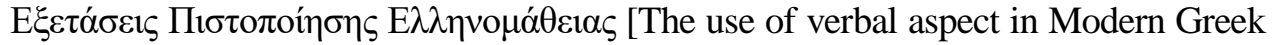

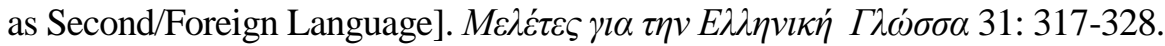

Mohamad-Nor N, Rashid RA (2018) A review of theoretical perspectives on language learning and acquisition. Kasetsart Journal of Social Sciences 39(1): 161-167.

Nicolaidis K, Andreou P, Bozonelos V, Mavroudi A, Theodorou D, Tasioudi M, Tsiantoula S (2011) Cross-linguistic influences in the acquisition of the phonetic/phonological system of Greek as a second/foreign language. In Proceedings of the 31st Annual Meeting of the Department of Linguistics, Faculty of Philosophy, Aristotle University, May 2010, 357-378. Thessaloniki: Aristotelian University.

O'Grady W, Cho SW (2011) First language acquisition. Pearson, Toronto, Canada.

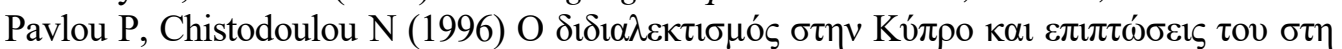

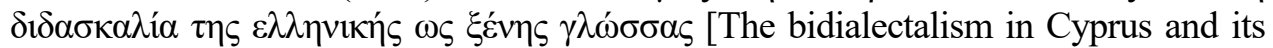
consequences in the instruction of Greek as a foreign language]. In Proceedings of the $16^{\text {th }}$ Annual Meeting of the Department of Linguistics of Aristotle University, 588597. Thessaloniki: Aristotle University.

Piske T, Flege JE, MacKay IRA, Meador D (2002) The production of English vowels by fluent early and late Italian-English bilinguals. Phonetica 59(1): 49-71.

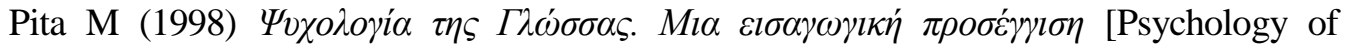
language. An introductory approach]. Athens: Ellinika Grammata.

Scovel T (2000) A critical review of the critical period research. Annual Review of Applied Linguistics 20: 213-223.

Snow C E (1987) Second language learners' format definitions: An oral language correlate of school literacy. Los Angeles: University of California, Center for Language Education and Research.

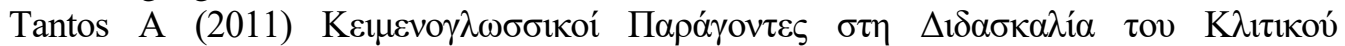

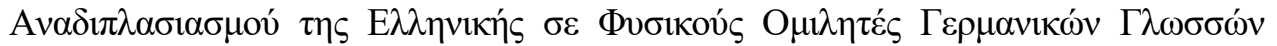
[Text-Lingual factors in the instruction of doubling clitics of Greek in native speakers

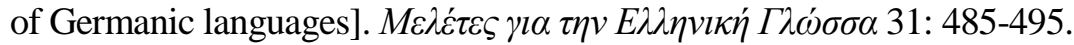

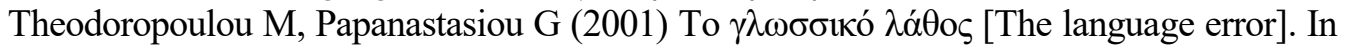

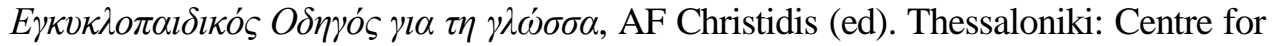
Greek Language.

Tsukada K, Birdsong D, Mack M, Sung H, Bialystok E, Flege JE (2005) Release bursts in English word-final voiceless stops produced by native English and Korean adults and children. Phonetica 61 2-3: 67-83.

Yiakoumetti A (2003) Bidialectism and Linguistic Performance in the Standard: The Case of Cyprus. Doctoral Thesis, UK, University of Cambridge.

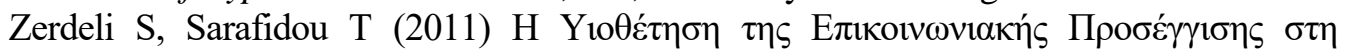

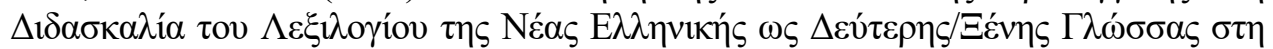

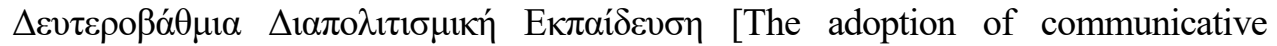
approach in the instruction of the vocabulary of Modern Greek as a second/foreign

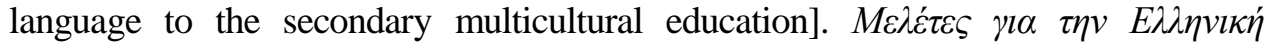
$\Gamma \lambda \omega ́ \sigma \sigma \alpha 31: 173-184$. 
